\title{
A PERCEPÇÃO TRIDIMENSIONAL COMO PARTE DO PROCESSO ENSINO-APRENDIZAGEM DO COMPONENTE CURRICULAR ESTRUTURAS DE AÇO NA UFERSA - CMPF
}

\author{
A THREE-DIMENSIONAL PERCEPTION AS PART OF THE TEACHING-LEARNING PROCESS \\ OF STRUCTURAL STEEL CURRICULAR COMPONENT AT UFERSA - CMPF \\ José Henrique Maciel de Queiroz ${ }^{1}$, Matheus Fernandes de Araújo Silva², \\ Hortência Pessoa Rego Gomes ${ }^{3}$ \\ DOI: 10.37702/REE2236-0158.v39p61-69.2020
}

\begin{abstract}
RESUMO
Este trabalho objetiva investigar o surgimento de dificuldades observadas entre os alunos do componente curricular Estruturas de Aço na Universidade Federal Rural do Semi-Árido, Centro Multidisciplinar Pau dos Ferros, em relação à interpretação de representações em duas dimensões de estruturas tridimensionais e os seus impactos no processo ensino-aprendizagem do componente. Tal investigação foi realizada com uma abordagem qualitativa, utilizando-se como ferramenta de obtenção de dados a entrevista aberta com o docente e com uma amostra de alunos matriculados no componente curricular. Os resultados mostraram que muitos alunos possuem a dificuldade mencionada e ela acarreta outros problemas no âmbito desse componente curricular. Assim, o sucesso das aulas e do aluno, em partes, depende dessa percepção tridimensional e o ideal é que o docente busque metodologias de ensino que supram essas necessidades dos alunos.
\end{abstract}

Palavras-chave: didática; percepção 3D; ensino-aprendizagem.

\begin{abstract}
This work aims to investigate the emergence of difficulties observed among students of the Structural Steel curricular component at the Universidade Federal Rural do Semi-Árido, Centro Multidisciplinar Pau dos Ferros, in relation to the interpretation of two-dimensional representations of three-dimensional structures and their impacts on the process teaching-learning component. This research was carried out with a qualitative approach, using as a tool to obtain data the open interview with the teacher and a sample of students enrolled in the curricular component. The results showed that many students have the mentioned difficulty and it causes other problems in the scope of the curricular component. Thus the success of the classes and the student, in parts, depends on this three-dimensional perception and the ideal is for the teacher to seek teaching methodologies that meet these needs of the students.
\end{abstract}

Keywords: didactics; 3D perception; teaching-learning. 


\section{INTRODUÇÃO}

$\mathrm{Na}$ Engenharia de Estruturas, a análise dos problemas relacionados ao dimensionamento de estruturas de aço requer, por muitas vezes, o perfeito entendimento das formas estudadas, as disposições construtivas e as conexões. É recorrente nos projetos o uso da representação simplificada das estruturas, em duas dimensões (2D).

Com isso, no meio universitário, os estudantes podem sentir algumas dificuldades relacionadas à interpretação das situações expostas pelo professor em $2 \mathrm{D}$, em que no dimensionamento estrutural devem ser consideradas as três dimensões. Nos desenhos, as linhas podem se confundir nos eixos cartesianos e algumas informações do desenho podem se sobrepor, demandando mais atenção na interpretação.

Esse tipo de dificuldade pode vir a ocasionar diversas consequências no rendimento do componente curricular. Sendo assim, esta pesquisa buscou identificar como surge tal dificuldade e como ela influencia no processo ensino-aprendizagem dos conteúdos do componente curricular Estruturas de Aço na Universidade Federal Rural do Semi-Árido (UFERSA), Centro Multidisciplinar Pau dos Ferros (CMPF).

Para tanto, realizou-se uma pesquisa de campo com os discentes e o docente do componente curricular citado anteriormente, entrevistando-os sobre os conteúdos, formas de ensino e o contexto no qual os discentes estão inseridos, colocando em pauta a problemática observada.

\section{METODOLOGIAS DE ENSINO}

O processo ensino-aprendizagem, segundo o pensamento de Barbosa (2001), será eficaz quando forem adotados os métodos e técnicas adequadas, esses dois aspectos que constituem propriamente a metodologia de ensino. A metodologia deve se adaptar às situações reais da sala de aula, como o assunto abordado, os recursos disponíveis para o professor e alunos, $o$ perfil $e$ as necessidades individuais $e$ coletivas desses últimos.
Brighenti et al. (2015) complementam essa afirmação ao mencionar que o processo educativo deve estar atrelado ao emprego de metodologias que permitam o alcance dos objetivos do ensino e da aprendizagem, permitindo assim a obtenção do máximo rendimento nesta relação didática.

Existem diversos métodos de ensino, os quais evoluíram ao longo da história de acordo com a finalidade que se almejava com o ensino e com o contexto socioeconômico, político e cultural de cada época, como afirma Damis (2010). Conheceremos a seguir um pouco mais sobre eles.

\section{Métodos e técnicas de ensino}

De maneira geral, o método é o caminho que será tomado para obtenção de um determinado objetivo. Libâneo (1994) diz que um professor pode utilizar um conjunto de ações, passos, condições externas e procedimentos para constituir o seu método de ensino. Entretanto, ao invés de se constituírem como receitas prontas, os métodos devem expressar a relação conteúdo-método. Assim, o método busca integrar as relações que permitam conhecer o objeto de estudo.

Os métodos de ensino são classificados sob a ótica de cada autor, conforme os critérios adotados por cada um. Libâneo (1994) realiza sua classificação em cinco métodos, segundo aspectos externos, que estão ligados à forma de conduzir o ensino:

1) Método de exposição pelo professor: o professor apresenta os conteúdos, conhecimentos, habilidades e tarefas; e o educando recebe essas informações de forma ativa ou passiva. É um método bastante criticado atualmente, mas que é efetivo quando combinado com outros procedimentos que individualizem o aluno e promovem conversação. Dentre os métodos expositivos podemos mencionar a exposição verbal, a demonstração, a ilustração e a exemplificação. 
2) Método de trabalho independente: pressupõe que o aluno possua conhecimentos e capacidades prévias para realizar as atividades propostas de forma parcialmente independente do professor, solicitando a sua orientação sempre que necessário. Explora as habilidades do aluno, testando suas capacidades e pode permitir que, por exemplo, em uma turma numerosa, cada aluno receba tarefas de acordo com o seu perfil e nível de domínio do assunto abordado. As tarefas podem ser preparatórias, de assimilação do conteúdo ou de elaboração pessoal.

3) Método de elaboração conjunta: valoriza a interação professor-aluno com o objetivo de se obter ou fixar conhecimentos, habilidades e convicções, partindo-se de um tema pré-definido em que os alunos tenham o mínimo de conhecimento acerca dele para prosseguir em um debate com sistematização e construção de opiniões e discussões. Pode ser adotado por meio da conversação didática ou aula dialogada.

4) Método de trabalho em grupo: é um método empregado eventualmente, em conjunto com os demais. Inicia-se com a proposta de diferentes temas de estudo para equipes geralmente pequenas de alunos que pesquisarão cooperativamente sobre a temática cuja familiaridade já tenha sido introduzida pelo professor por meio de exposição, conversação ou trabalho individual. Para a obtenção de sucesso, costuma-se realizar a comunicação dos resultados obtidos pelas equipes de forma aberta para a turma.

5) Atividades especiais: complementam os métodos citados e explora a assimilação ativa do aluno, por meio de instrumentos escolares diversos como o jornal escolar, estudos de caso, o teatro, a biblioteca e outros.
No que diz respeito às técnicas de ensino, podemos afirmar que elas constituem o meio pelo qual será efetivado o método de ensino adotado, ou seja, é como se faz para aplicar de maneira satisfatória tal método a partir de procedimentos concretos. Evidentemente, estes dois conceitos são indissociáveis.

Alguns autores, como Barbosa (2001), classificam as técnicas de ensino em três:

1) Técnicas expositivas ou de comunicação: possuem como característica principal a transmissão de uma mensagem codificada em linguagem, ilustração, símbolos visuais ou sonoros. Podem ser realizadas pelo professor, em grupo ou coletivamente e a mensagem transmitida pode vir com ideias mais ou menos estruturadas.

2) Técnicas de interrogação ou indagação: baseiam-se no diálogo e no confronto de opiniões e ideias sobre um tema em específico, com o objetivo de discuti-lo profundamente. Também se utiliza da comunicação entre os indivíduos que sempre se concentram sobre uma dúvida, uma indagação que pode levantar opiniões variadas entre os participantes do debate.

3) Técnicas de pesquisa ou experimentação: bastante empregadas em estudos individuais e também em pequenos grupos de alunos. Apresentam grande rendimento por compreender etapas essenciais para qualquer atividade científica, iniciando-se com a busca sobre os conceitos fundamentais sobre o tema, para posterior análise e síntese, sendo esta última comunicada à turma como resultado.

\section{Recursos didáticos}

A metodologia de ensino está atrelada ainda aos recursos didáticos disponíveis. Karling (1991) explica os recursos didáticos como sendo recursos tanto humanos quanto 
materiais utilizados pelo professor em sua atividade profissional, com o objetivo de auxiliar e facilitar a aprendizagem do estudante. Dentre as várias denominações que se referem a essas ferramentas temos: meios didáticos, meios auxiliares, material didático, recursos audiovisuais, multimeios e material instrucional.

Ainda de acordo com o pensamento de Karling (1991), os recursos didáticos são importantes para que o educando receba informações a partir dos seus sentidos para que se transformem em percepções, seja por meio de imagens, fatos, situações, experiências, demonstrações etc. Segundo o autor, uma imagem, por exemplo, pode, além de economizar palavras, permitir que o aluno sinta algo tal como a coisa é, sem ficar restrito apenas à imaginação da constituição feita pelas palavras do professor.

O aluno precisa vivenciar situações concretas para poder extrair o máximo de ideias, obter subsídios para pensar, raciocinar, criar e resolver problemas. Nesse sentido, os recursos didáticos podem proporcionar oportunidades únicas aos estudantes, uma vez que algumas situações, fatos ou imagens seriam difíceis ou até mesmo impossíveis de serem vivenciadas pessoalmente pelo aluno. (KARLING,1991).

$\mathrm{Na}$ medida em que um objeto, por exemplo, pode ser visto, tocado e manipulado pelo aluno, ocorre uma aproximação maior da realidade, tornando a experiência do aprendizado mais concreta e significativa. Neste mesmo exemplo podemos destacar ainda como o aluno pode assimilar melhor tamanhos, formas, estruturas e o funcionamento de equipamentos (KARLING,1991).

Devido a essas características, os recursos didáticos assumem também um papel de incentivador. Ao instigar o aluno sobre determinada situação, os recursos didáticos podem fazê-lo prestar mais atenção na aula, levantar questionamentos e hipóteses e desenvolver pesquisa. O uso do recurso didático adequado pode estimular no aluno o gosto pelo estudo e por determinadas áreas de conhecimento de uma forma que pode ser lembrada positivamente por toda a vida. (KARLING,1991).

\section{PROCEDIMENTOS METODOLÓGICOS}

Para se alcançar os objetivos desta pesquisa, adotou-se como metodologia a pesquisa de campo, ou seja, foram realizadas visitas, observações e entrevistas in loco, visando à aquisição de informações e de evidências pertinentes ao tema abordado para embasamento das discussões posteriores.

Quanto à forma de abordagem do problema, tem-se uma pesquisa de caráter qualitativo. Sendo assim, foi avaliada a opinião dos discentes e do docente da turma quanto ao problema investigado, expondo as observações mais relevantes feitas durante a pesquisa. Além disso, foram identificados os recursos didáticos adotados pelo docente e a importância desse tipo de interação no processo ensino-aprendizagem.

A pesquisa qualitativa busca analisar e interpretar os dados em seu caráter psicossocial, considerando que exista uma relação dinâmica entre o mundo real e o sujeito (ASSIS, 2008).

Entre os quatro campi da UFERSA, o Centro Multidisciplinar Pau dos Ferros foi selecionado como sendo campo de estudo desta pesquisa. O município de Pau dos Ferros situa-se no interior do estado do Rio Grande do Norte, a $398 \mathrm{~km}$ da sua capital, Natal. Para um melhor reconhecimento do local, a Figura 01 nos mostra a vista aérea do referido campus, às margens da rodovia BR-226.

Figura 01 - Vista aérea UFERSA CMPF

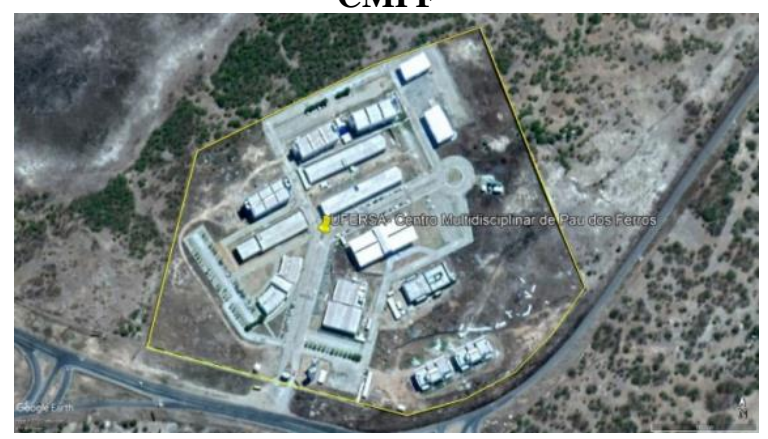

Fonte: Google Earth, 2018. 
A coleta dos dados necessários para a obtenção dos resultados e suas discussões foi proveniente da turma de Estruturas de Aço (PEX0288), matriculada no semestre letivo 2018.1 do curso de Bacharelado em Engenharia Civil no CMPF da UFERSA. Entende-se por turma o conjunto de discentes matriculados no componente curricular Estruturas de Aço bem como o seu regente.

A referida turma era composta por 44 alunos regularmente matriculados, dos quais selecionou-se uma amostra aleatória com a quantidade de seis alunos, utilizando-se como método de amostragem a saturação teórica das respostas, encerrando a coleta de dados no momento em que as respostas dos participantes se tornam repetitivas. Saturação, neste contexto, é um termo criado por Glaser e Strauss (1967) para se referirem ao momento da pesquisa em que a coleta de novos dados, por entrevistas e questionários, por exemplo, não traria mais esclarecimentos para o objeto estudado.

$\mathrm{O}$ desenvolvimento da pesquisa foi executado em etapas até o alcance dos seus objetivos. Primeiramente, foi realizada a pesquisa bibliográfica acerca do tema, utilizando-se recursos digitais para busca de bibliografia correlacionada à proposta da pesquisa, como sites, artigos em revistas, periódicos, teses e dissertações. Buscou-se, também, materiais impressos como livros, revistas e manuais. Esse referencial foi importante para entender o que já foi discutido sobre o assunto e para embasar as discussões posteriores sobre resultados.

Depois disso, elaborou-se o roteiro para as entrevistas, no qual foram elencadas perguntas pertinentes à investigação, que serviram como base para efetuação das entrevistas.

$\mathrm{O}$ intuito das entrevistas foi propor aos discentes questionamentos quanto à existência de dificuldades associadas ao entendimento dos assuntos abordados no componente curricular e o impacto que isso pode causar no seu desempenho acadêmico.

Com o docente, buscou-se identificar sua percepção sobre a turma. Com isso, surgem perguntas que buscam diagnosticar a situação dos alunos (agora na visão do docente) diante da problemática e suas dificuldades em assimilar os conteúdos; identificar os recursos didáticos empregados nas aulas de Estruturas de Aço; e, também, sua relação com o componente curricular.

Essas entrevistas foram conduzidas pelo autor de forma semiestruturada. Com a participação de seis discentes foi possível se verificar a saturação das informações fornecidas pela amostra. $\mathrm{O}$ docente foi entrevistado em seguida.

Posteriormente, esses dados receberam a devida análise e as entrevistas que haviam sido gravadas em áudio foram transcritas com a finalidade de mais rápida identificação e comparação das respostas coletadas. Analisados e com suas discussões feitas, esses dados são apresentados adiante, conciliando as opiniões dos entrevistados com pensamentos de outros autores desta mesma área de pesquisa.

\section{A PROBLEMÁTICA E SUAS CONSEQUÊNCIAS NO PROCESSO ENSINO-APRENDIZAGEM}

Executadas as etapas descritas anteriormente, pode-se destacar vários aspectos do processo ensino-aprendizagem do componente curricular Estruturas de Aço na UFERSA - CMPF, verificados diretamente com os participantes da turma no semestre 2018.1. Para iniciar essa discussão, abordaremos a constatação da problemática em questão.

Em relação a isso, podemos afirmar que, de fato, muitos alunos possuem dificuldade em visualizar, analisar e interpretar representações 2D durante as atividades do componente curricular em estudo, seja durante exemplos ou exercícios de dimensionamento, assim como nas avaliações de desempenho estudantil. Quando questionados sobre isso, todos os alunos consultados afirmaram já haver passado por essa situação em algum momento.

Um dos entrevistados relata que no início das aulas desse componente curricular - que é um período em que há menor conhecimento sobre as estruturas por parte do aluno -, essa 
dificuldade era a maior enfrentada: "Bem no começo da disciplina (sic) a minha maior dificuldade era de interpretar o que estava sendo desenhado, o tipo de estrutura que ele estava tentando mostrar".

Os desenhos a que se refere o entrevistado são executados pelo professor na lousa, com boa qualidade - segundo a opinião dos alunos -, mas, ainda assim, eles possuem dificuldades em relacionar o desenho à estrutura real, a partir de sua imaginação. Portanto, a qualidade do desenho na lousa não seria o que leva às dúvidas por parte dos discentes.

Quando se fala sobre o motivo da existência desta problemática, alguns afirmam que é algo que está associado ao próprio conteúdo do componente curricular que envolve conceitos complexos que podem ser confundidos nos eixos coordenados das estruturas, a exemplo dos comprimentos de flambagem. Enquanto isso, outros associam principalmente à falta de convivência do discente com as estruturas metálicas; ou seja, para estes, trabalhar com esse tipo de estrutura seria algo novo e os próprios perfis utilizados seriam desconhecidos em sua forma real.

Questionados sobre sua experiência com as construções em estruturas de aço, os participantes demonstram pouca intimidade ou convivência com elas. As experiências relatadas se reduzem a visitas em obras compostas desse material durante estágio curricular ou somente no próprio componente curricular Estruturas de Aço, em que o docente promoveu uma visita técnica em uma obra do tipo.

Isso mostra que a situação apontada por Karling (1991) se aplica no componente citado, uma vez que com o pequeno ou nenhum contato dos alunos com a estrutura metálica real, os recursos didáticos tornam-se a principal forma de interação do discente com a estrutura propriamente dita. Eleva-se, assim, a importância da utilização de recursos que permitam a devida aproximação entre as teorias e as situações reais.

No geral, a dificuldade de acesso a essas obras se deve ao fato de que existem poucas construções projetadas com estruturas metálicas na região em que se situa o Centro
Multidisciplinar Pau dos Ferros, pois nas obras locais, segundo os entrevistados, predominam estruturas de concreto armado, exceto em coberturas de postos de gasolina, ginásios poliesportivos e outros. Mesmo os alunos que moram em outras cidades de pequeno porte afirmam que é difícil conseguir acesso a estruturas desse tipo.

De acordo com Fonseca (2015), a utilização de estruturas de aço como tecnologia construtiva encontra-se em desenvolvimento no mercado de Engenharia Civil brasileiro e representa cerca de $15 \%$ do universo do setor de edificações no Brasil. Esse valor já é bastante considerável. Porém, em cidades pequenas, ainda é notável a prevalência das estruturas de concreto armado.

Além disso, o docente do componente ressalta um ponto que pode inclusive prejudicar o aprendizado do discente, ao mencionar que há também a dificuldade de se encontrar, entre as poucas construções em aço existentes na região, alguma adequadamente concebida e que disponha de projeto estrutural para consulta, não podendo então ser utilizadas como exemplo para o aprendizado.

Caso o discente venha a analisar uma estrutura mal concebida e a tome como referência para o seu aprendizado, isso pode levá-lo a cometer erros similares no futuro e até mesmo leva-lo a não assimilar as situações de projeto discutidas no componente curricular corretamente, por divergirem do observado em campo.

Assim, dada a existência da dificuldade por parte do aluno em entender as representações $2 \mathrm{D}$ de forma rápida e efetiva problema este observado pelo docente tanto durante suas aulas quanto também durante as avaliações escritas -, resolvemos verificar também o impacto desse aspecto no desempenho acadêmico dos participantes da entrevista.

Nesse caso, todos os discentes entrevistados afirmaram que pode haver sim um impacto negativo decorrente da má interpretação das representações 2D. O participante 02 comenta que para resolver as questões de prova é necessário entender todas as características da estrutura, onde haverá 
flambagem, torção, travamentos etc. $\mathrm{O}$ discente, por vezes, recorre a objetos ao seu alcance, como a régua, na tentativa de representar perfis de aço. $\mathrm{O}$ docente concorda com a afirmação do participante; para ele, só se consegue resolver o problema quando há compreensão da estrutura, então o discente só consegue mostrar o que aprendeu se ao menos superar essa dificuldade.

Outros discentes, como o participante 04, possuem a visão de que além do impacto sobre as suas notas, há também um prejuízo relacionado à habilidade de se realizar a concepção das estruturas e este considera de grande importância para o discente, no âmbito do componente curricular, adquirir essa capacidade de entendimento dos projetos e do funcionamento da estrutura em si.

Essa importância pode ser traduzida diante do objetivo do componente curricular, que indiretamente requer estas habilidades do educando:

\footnotetext{
Apresentar ao aluno conceitos de dimensionamento dos principais elementos estruturais de aço submetidos à tração, compressão, flexão simples e composta. $\mathrm{O}$ dimensionamento $\mathrm{e}$ verificações são feitas considerando o Método dos Estados Limites Últimos. Além disso, são apresentados detalhes típicos de estruturas metálicas e a forma como devem ser apresentados para execução em uma obra. (UFERSA, 2018, p. 1)
}

Ainda se tratando das consequências que A nossa problemática de estudo pode vir a ocasionar, citamos também a má utilização do tempo de aula, disponível para a apresentação dos conteúdos previstos para o componente curricular. Nesse ponto, o docente aponta que a depender do tipo de exercício realizado em sala de aula, ou seja, quando a resolução depende muito da visão tridimensional da estrutura, há recorrência de interrupções durante sua resolução para esclarecimento de dúvidas dos discentes sobre a composição da própria estrutura ao invés de sobre o conteúdo proposto para a aula. Isso leva o docente a buscar outras formas de representar o problema, por meio de fotos semelhantes, por exemplo, o que ainda não soluciona tão facilmente a dúvida.

Para que fossem explanados e discutidos de forma apurada todos os conteúdos indicados na ementa do componente curricular, o docente considera que necessitaria de uma carga horária maior do que a atual (60 horas), podendo facilmente dividir esses conteúdos em dois componentes, totalizando uma carga horária de 120 horas. Assim, atualmente, mesmo filtrando alguns conteúdos, o cronograma exige uma aula planejada para um ótimo aproveitamento de todo o tempo. Entretanto, quando o aluno não entende a representação do problema logo de início, há várias interrupções solicitando nova explicação e promovendo o atraso na aula.

A seguir podemos consultar o Conteúdo Programático do componente curricular Estruturas de Aço (PGCC) da UFERSACMPF:
a) generalidades;
b) critérios de dimensionamentos $\mathrm{e}$ cargas;
c) propriedades;
d) introdução ao estudo dos perfis de chapa dobrada a frio;
e) dimensionamento de perfis laminados;
f) dimensionamento de barras tracionadas;
g) dimensionamento de barras comprimidas;
h) dimensionamento de barras fletidas;
i) dimensionamento de barras submetidas à solicitação composta (Flexocompressão e Flexotração);
j) ligações.

Tulio (2013) acredita que é uma atribuição dos profissionais da educação buscar por alternativas para tornar o ensino mais atraente para os educandos, levando-os a enxergar o ambiente escolar como um espaço onde ele possa construir o conhecimento baseado tanto nos recursos didáticos usuais quanto, também, em recursos tecnológicos, os quais estão presentes em muitos segmentos de nossa vida.

Com isso, uma das alternativas que o docente do componente curricular Estruturas de Aço utiliza para otimização de sua aula e 
melhor assimilação dos conteúdos por parte dos discentes é o uso de recursos didáticos diversos, os quais foram identificados durante esta pesquisa. Vejamos abaixo a listagem desses recursos:
a) a própria voz;
b) quadro-branco;
c) ilustrações, sob a forma de desenhos, gravuras e fotografias;
d) projeções de slides;
e) vídeos via portal web;
f) materiais impressos, como apostilas e catálogos;
g) softwares;
h) modelos estruturais.

Logo, percebe-se uma diversidade de recursos integrantes da didática do docente, que vão dos mais elementares a outros bem mais sofisticados, como softwares, vídeos e modelos estruturais. Em especial, os modelos estruturais citados são instrumentos que possuem emprego bastante específico para esse componente curricular e demais componentes relacionadas à Engenharia de Estruturas. Eles representam vigas, pórticos e treliças em escala reduzida e se constituem de materiais que permitem visualizar melhor o comportamento das estruturas quando submetidas a carregamentos.

\section{CONCLUSÕES}

Com base nas informações apresentadas anteriormente - os depoimentos dos discente e docente, além das ideias defendidas pelos demais autores -, reiteramos a importância do adequado emprego de metodologias de ensino, que estejam de acordo com os objetivos das aulas e do componente curricular em curso. Um docente bem preparado identificará as necessidades da turma e dos conteúdos abordados buscando soluções que facilitem o aprendizado dos alunos.

Dos resultados pôde-se perceber que a percepção tridimensional das estruturas metálicas em representações 2D pode realmente ser uma dificuldade para muitos alunos e que, além disso, afeta várias dimensões do componente curricular, entre elas, principalmente: o rendimento do aluno em avaliações; a aprendizagem relacionada à concepção de estruturas metálicas; e o uso do tempo de aula disponível. Uma das estratégias que colaboram para a resolução desse problema, segundo o docente, tem sido a utilização de recursos didáticos complementares, conforme comentado anteriormente.

Por fim, notamos que todos os objetivos dessa pesquisa foram alcançados e a ela contribui com o meio científico e acadêmico por colocar em discussão uma temática que por muitas vezes não recebe a devida atenção dos docentes, mas que também influencia diretamente no processo ensino-aprendizagem do componente curricular Estruturas de Aço.

\section{REFERÊNCIAS}

ASSIS, M. C. Metodologia do trabalho científico. 2008. Disponível em: <http://biblioteca.virtual.ufpb.br/files/met odologia_do_trabalho_cientifico_1360073 105.pdf> Acesso em: 11 ago., 2018.

\section{BARBOSA， P. O. D. Recursos didáticos aplicados nos cursos de qualificação profissional: um estudo de caso no CEFET-PR. 2001. Dissertação (Mestrado) - Curso de Engenharia de Produção, Universidade Federal de Santa Catarina, Florianópolis, 2001.}

BRIGHENTI, J. et al. Metodologias de ensinoaprendizagem: uma abordagem sob a percepção dos alunos. Revista GUAL, Florianópolis, 8(3), p. 281-304, 2015.

\section{DAMIS, O. T. Repensando a didática. Campinas: Papirus, 2010.}

FONSECA, C. Estrutura metálica é aposta na construção. Centro Brasileiro da Construção do Aço (CBCA). 2015. Disponível em: <http://www.cbcaacobrasil.org.br/site/noticiasdetalhes.php?cod=7072. Acesso em: 03 jun., 2018. 
GLASER, B.; STRAUSS, A. The discovery of grounded theory: strategies for qualitative research. New York: Aldine Publishing Company, 1967.

KARLING, A. A. A didática necessária. São Paulo: IBRASA, 1991.

LIBÂNEO, J. C. Didática. São Paulo: Cortêz, 1994.

TULIO, M. Recursos didáticos e sua importância para as aulas de geociências no $6^{\circ}$ ano do ensino fundamental (Colégio Estadual Antonio e Marcos
Cavanis/Castro-PR). Os Desafios da Escola Pública Paranaense na Perspectiva do Professor PDE, Paraná, n. 1, 2013. Disponível em: <http://www.diaadiaeducacao.pr.gov.br/p ortals/cadernospde/pdebusca/producoes_p de/2013/2013_uepg_geo_artigo_mariliz_t ulio.pdf>. Acesso em: 01 set., 2018.

UFERSA, Universidade Federal Rural do Semi- Árido. Programa Geral de Componente Curricular: Estruturas de Aço. Pau dos Ferros-RN, 2018.

\section{DADOS BIOGRÁFICOS DOS AUTORES}
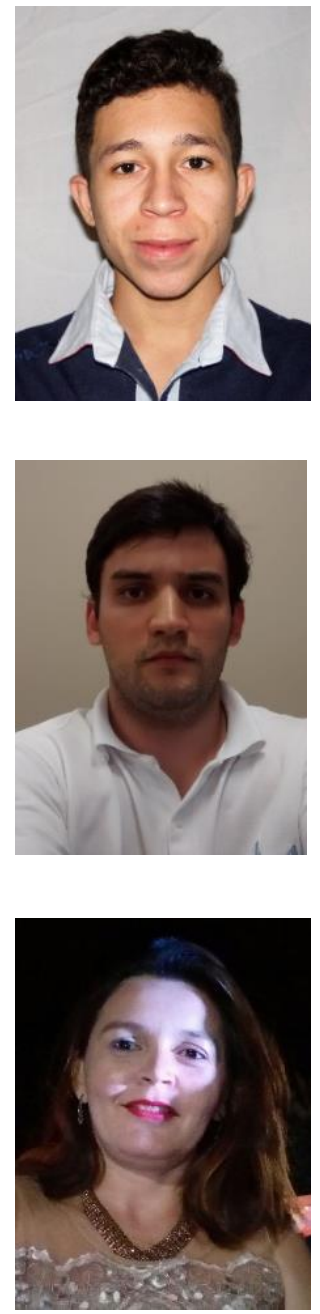

José Henrique Maciel de Queiroz - Bacharel em Ciência e Tecnologia em 2016 e em Engenharia Civil em 2018, ambos pela Universidade Federal Rural do SemiÁrido - UFERSA. Atualmente, professor na UFERSA Centro Multidisciplinar Pau dos Ferros com área de concentração em Engenharia de Estruturas e Geotecnia.

Matheus Fernandes de Araújo Silva - Graduado em Engenharia Civil pela UFRN em 2011. Mestre em Engenharia de Estruturas em 2013 pela USP - Escola de Engenharia de São Carlos. Doutorando em Engenharia de Estruturas desde 2013 pela mesma instituição. Atualmente, professor na UFERSA, Centro Multidisciplinar de Pau dos Ferros. Possui interesse no comportamento ao cisalhamento e em simulação numérica de estruturas de concreto armado.

Hortência Pessoa Rêgo Gomes - Graduada em Pedagogia pela Universidade do Estado do Rio Grande do Norte (2002). Curso de Geografia em andamento. Especialização em Educação Ambiental e Geografia do Semiárido, pelo Instituto Federal de Educação Tecnológica do Rio Grande do Norte, IFRN (2010). Mestrado Acadêmico em Ensino do Programa de Pós-Graduação em Ensino - Área de Ensino de Ciências Humanas e Sociais da UERN. Atualmente, pedagoga da Universidade Federal Rural do Semiárido. Tem experiência na área de Educação Básica e Educação Superior, com ênfase em Educação. 